\title{
The Transmission Mechanism and Prospect of China's Standing Lending Facility
}

\author{
Runjia Zeng, Pu Liu* \\ School of Economics, Jinan University, Guangzhou, China \\ Email: locke1993@163.com, *lpgauss@163.com
}

How to cite this paper: Zeng, R.J. and Liu, P. (2017) The Transmission Mechanism and Prospect of China's Standing Lending Facility. Journal of Service Science and Management, 10, 125-131.

https://doi.org/10.4236/jssm.2017.102011

Received: February 23, 2017

Accepted: April 10, 2017

Published: April 13, 2017

Copyright $\odot 2017$ by authors and Scientific Research Publishing Inc. This work is licensed under the Creative Commons Attribution International License (CC BY 4.0).

http://creativecommons.org/licenses/by/4.0/

\begin{abstract}
People's Bank of China created the Standing Lending Facility (SLF) in June, 2013. As a tool of monetary policy, standing lending facility is created to maintain the stabilization of monetary market and help country's economy develop steadily. In developed countries, tools like SLF have already been used much earlier than China, so this time I will use their research methods and try to study the transmission mechanism of China's SLF. Meantime, in the background that China is carrying forward market-based reform of interest rates, the application prospect of SLF will be at the same time discussed.
\end{abstract}

\section{Keywords}

Standing Lending Facility, Transmission Mechanism, Prospect, Interest Rate, Liquidity

\section{Introduction}

At the beginning of 2013, People's Bank of China created a new monetary policy tool, the standing lending facility (SLF). Generally, SLF is a central bank's monetary policy instrument which can control market liquidity. It was created mainly for bank system's need to ease short-term liquidity tight. What's more, commercial banks can apply SLF from central bank easily only if they could supply high credit rating of bond assets and high quality credit assets as collateral.

To China, Standing lending facility may be a new thing, but in western countries, monetary policy tools such as lending facility have existed for a long time, just in different names. For example, Federal Reserve's discount window, European Central Bank's marginal lending facilities, and the operational standing facility of the Bank of England, all of them are similar to China's SLF [1].

Standing monetary policy tools play roles of normal liquidity supply channels of China's central bank, the main function of them is to meet the large and long 
period (about 1 - 3 months) liquidity requirements of financial institutions. These financial institutions include policy banks and national commercial banks. The level of interest rates is determined according to the monetary policy and the need to guide interest rate of market. Standing lending facility enables mortgage disbursed, eligible collateral including high credit rating of the bond asset class and high-quality credit assets. Generally speaking, the standing lending convenience has these features: first, the financial institutions need to take the initiative to apply according to their own liquidity; second, central bank and financial structure apply "one to one" transaction; third, SLF has a wide range of counterparty coverage. Based on the former analysis, this paper introduces the transmission mechanisms of SLF in China. In section 3, after comparing different situations, I find that because of the interest rate control in Chinese monetary market, liquidity will be the main transmission mechanism of SLF. In section 4, I make some comments on the prospect of SLF based on other scholars' opinion. At last, section 5 will introduce the conclusions of this whole paper.

\section{Introduction of the Application of Domestic and International Standing Lending Tools}

\subsection{The Application of SLF Tools in Developed Countries}

As standing lending tools have already existed in developed countries for a long time, there are many examples about the use of them. Take the 2008 US financial crisis as atypical example. After the outbreak of the crisis, the US financial markets were hit hard (see Figure 1) and panic spread to the real economy. In order to get the United States out of the crisis as soon as possible, the Fed used all monetary policy tools, including interest rate cuts, open market operations, and discount rates adjustments [2].

From September 2007 to December 2008, nine cuts in interest rates cut the federal funds target rate by 500 basis points, and the degree was so unprecedented. But these measures did not achieve desired results, the market risk premium still did not return to normal levels. This urgent situation forced the Fed-

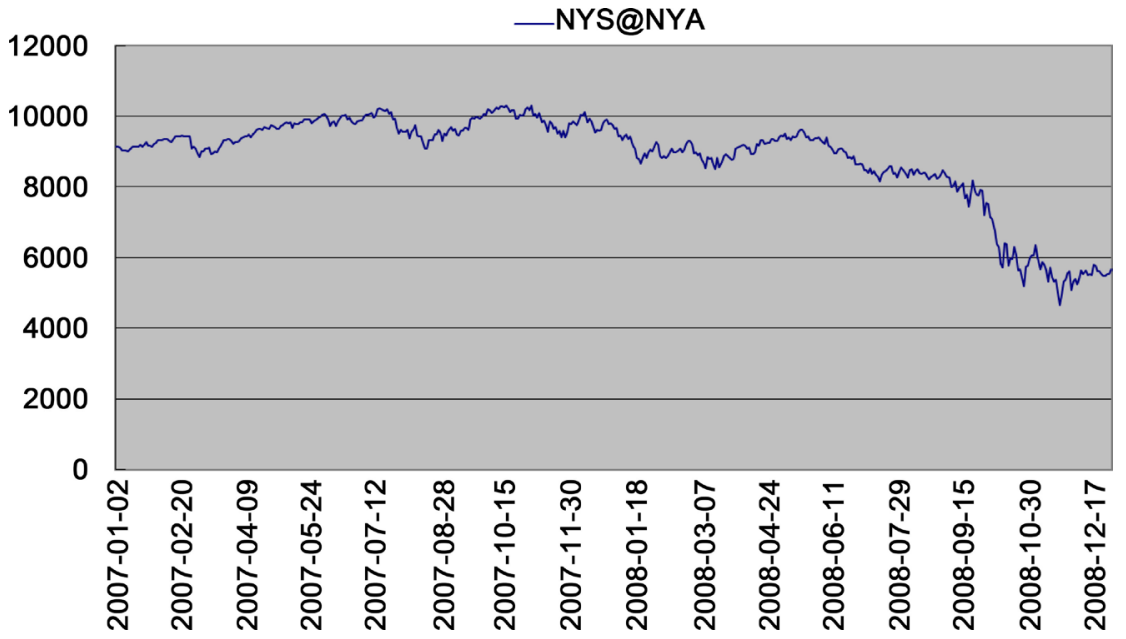

Figure 1. New York composite index from 2007 to 2008. 
eral Reserve to take further measures to create new monetary policy tools. The Federal Reserve mainly expanded and innovated the lending convenience monetary policy tools from four aspects: for the depository institutions, there are TAF and other tools; for a dealer, there are PDCF, TSLF and other tools; for the money market, AMLF, MMIFF and other tools were deposited, and CPFF and TABSLF for enterprises and legal entities with specific systemic risks [3]. In addition, for the collateral and borrowing period of these instruments, the Fed also adjusted to varying degrees [4].

In Europe, the ECB (European Central Bank) uses MLF (marginal lending facility) as short-term liquidity control tool, and it is used at the discretion of the Euro system's counterparties just like SLF. By adjusting MLF's interest rate, the ECB creates a "corridor" or "band" for the overnight rates. As interest rate been controlled, market liquidity will be influenced, too.

In a word, SLF-liked monetary tools have three characters in common: first, applying or not is decided by commercial banks, which makes it more flexible; second, its operational rate can guide market lending rate, which makes it a real policy monetary tool; third, mortgaged assets needed are easy to obtain.

\subsection{The Application of SLF Tools in China}

According to the information disclosed by the People's Bank of China, before the Spring Festival in 2013, the central bank augmented the standing loan to facilitate the settlement of some commercial banks due to the large amount of cash generated by the cash gap. In June, according to national industrial policies and macro-prudential requirements, the People's Bank of China (PBOC) provided liquidity support to financial institutions which support the real economy and operate steady during the event that currency markets were affected by the effects of multiple factors superimposed. To the relatively stable financial institutions which had liquidity management problems, the PBOC also took appropriate measures to provide liquidity support to them to maintain financial stability.

\section{Introduction to the Transmission Mechanism of SLF Tools}

After creating a new monetary policy tool, its transmission mechanism will be widely concerned and researched. Before examining the transmission mechanism of domestic regular lending facility monetary policy tools, we first review the foreign research results.

Generally speaking, the developed countries have two views on the transmission mechanism of lending facility tools. One considers that lending facility tools affect the real economy mainly through influencing the interest rate level. The central bank uses regular lending tools to trade with banks, which can influence short-term and long-term interest rates by adjusting the duration and type of collateral. Based on the Keynesian currency transmission mechanism theory, the lower long-term interest rate can promote investment, and ultimately promote real economic growth.

Another point considers that lending facility tools affect the real economy by 
providing liquidity to the market. According to Radcliffe's theory, when financial intermediaries such as commercial banks have high liquidity, they will compete to expand the scale of loans and increase the amount of money held by the public, eventually leading to an increase in the total social expenditure and affecting overall social economic activity. For example, the Federal Reserve has reduced the rediscount rate after the outbreak of the subprime mortgage crisis, which reduces the cost of capital borrowed by financial institutions, and meets the liquidity needs of financial institutions finally.

\subsection{The Impact of Standing Lending Facilities on Interest Rates in China}

To examine the impact of standing lending facilities on China's interest rates, we must first make it clear that China's benchmark deposit rate has not yet been liberalized. Therefore, it does not make sense to examine the impact of standing lending facilities on deposit rates. So, I introduced the Loan Prime Rate (LPR) as a measure of the impact of standing lending facilities on interest rates.

Loan base rate is an interest rate which commercial banks lend money to its highest quality customers, other loan interest rates can be generated by the addition and subtraction of it. The centralized quotation and distribution mechanism of the loan base interest rate are based on the independent interest rate of the loan base of the Bank, and the average interest rate of the loan base interest rate quotation is calculated by the designated issuer to calculate the weighted average of the quotation and make the announcement. At the beginning of the operation commercial banks announced 1-year loan base rate to the community. Since the loan base rate is not regulated but is self-quoted by commercial banks, it can respond to market interest rates well. Figure 2 shows the operating balance of the long-term lending facility; Figure 3 shows the central bank's oneyear loan base rate.

By comparing these two graphs, we cannot conclude that the operating balance of the standing landing facilitation tool has an expected impact on the loan interest rate. During the rise in the base rate of the loan base, it is presumably in February 2014, the operating balance of the standing landing facilitation tool

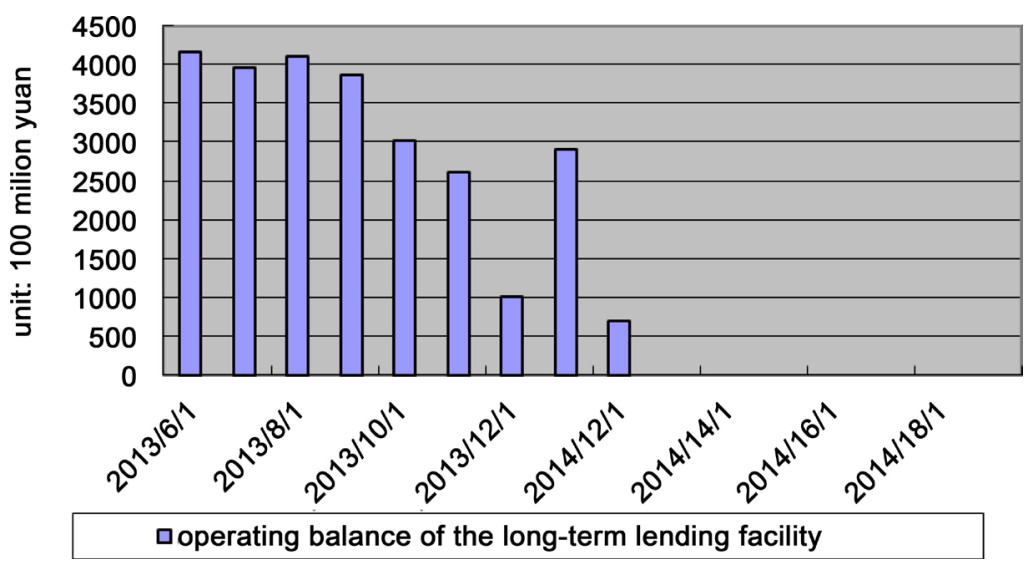

Figure 2. Operating balance of the long-term lending facility. 


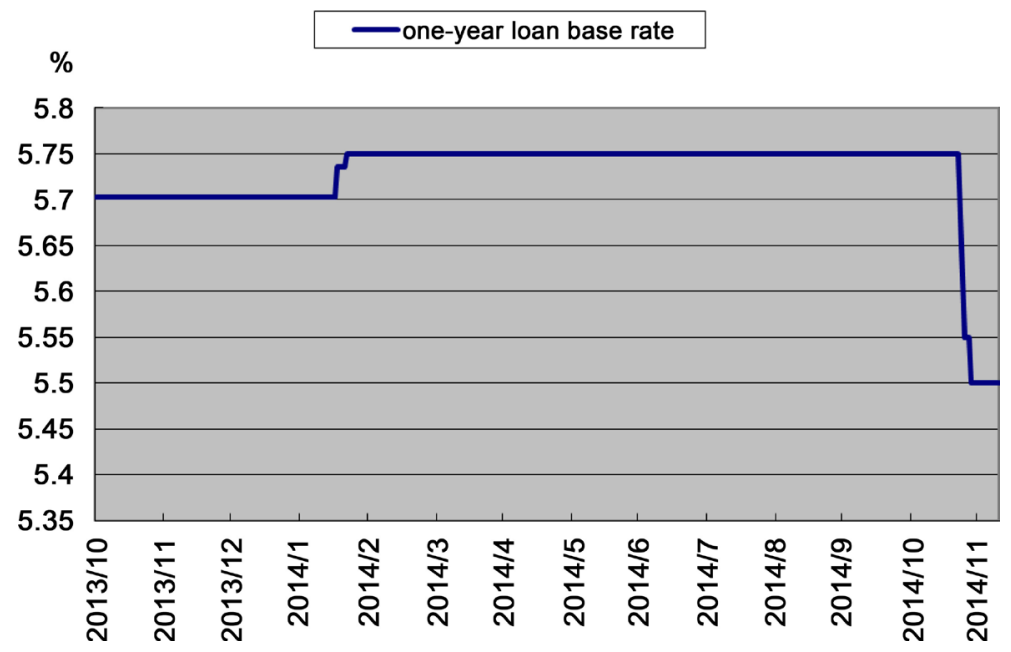

Figure 3. Central bank's one-year loan base rate.

experienced a sudden rise. But there is no evidence that the stabilization of the loan base rate is due to the reasons for the operation of the active landing tool. After that, the lending rate suddenly declined in November, but the central bank did not operate the landing facility at this time. Due to the inability to obtain the operating interest rate data, it is not possible to determine whether the active landing facility tool has an impact on the loan interest rate only from the operation balance observation.

\subsection{The Impact of Standing Lending Facilities on Liquidity in China}

With regard to the impact of landing facility tools on liquidity, some scholars focused on the impact of the Federal Reserve's newly created landing facility TAF on market liquidity risk premiums in the 2008 subprime crisis [5]. They adopt the Libor-OIS spread as a measure of market liquidity, and make a conclusion that, the greater the spread, the greater the liquidity risk premium [6]. Similarly, I will use the 3-month Shibor and overnight interest between the Shibor to measure the market's short-term liquidity risk premium.

The Shanghai Interbank Offered Rate (Shibor) is calculated and named by the national interbank lending center in Shanghai. It is an arithmetic average interest rate generated by the RMB interbank borrowing rate, which calculated by the banks with high credit rating. The average interest rate is a single profit, unsecured, wholesale interest rate. At present, Shibor varieties which published to community include overnight, 1 week, 2 weeks, 1 month, 3 months, 6 months, 9 months and 1 year. The data of 3-month Shibor and overnight interest between the Shibor obtained are shown in Figure 4.

From Figure 4 we can see that in June 2013, the spreads between 3-month Shibor and overnight Shibor suddenly increased, indicating that the inter-bank liquidity in the period of time suddenly tightened. At the same time, in June 2013, the central bank created the standing landing facility monetary policy tool, then, Shibor spreads gradually returned to normal levels. Another large spread occurred in January 2014, at this time, the operating balance of standing landing 


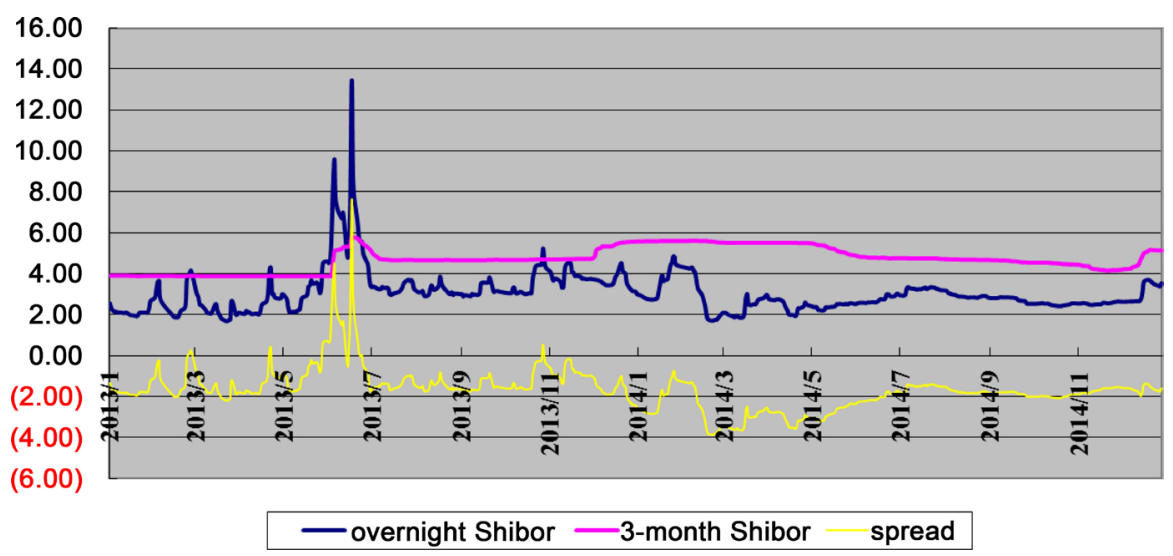

Figure 4. Spreads between 3-month Shibor and overnight Shibor.

facility tools suddenly increased from 100 billion yuan to nearly 300 billion yuan, spread of interest rates increase, but this time the increase is not as large as June 2013. On the other hand, we can infer that standing landing facilitate tools also play a role in stabilizing the market confidence. To sum up, we conclude that standing lending facilitation plays an important role in mitigating the short-term liquidity crisis of banks.

\section{Discussion on the Application Prospects of Standing Loan Facility}

In recent years, due to the reduction of liquidity caused by foreign exchange and the balance of assets and liabilities of the interbank business, the uncertainty factors faced by banks have increased and the probability of occurrence of liquidity crisis has increased greatly [7]. For example, in June 2013, there was an abnormal increase in the interbank offered rate in Shanghai. Therefore, it is necessary for the central bank to borrow liquidity facilities directly to the banks to provide liquidity, ease the short-term crisis. However, does the central bank create a standing landing facility only to ease the short-term liquidity crisis?

With China's economy growth speed turns down, the previous economic growth model has been difficult to sustain, reform the old way of economic growth has been imperative, which, interest rate marketization will be a very important part. In the case of lending rates have been fully liberalized, the full liberalization of deposit rates is only a matter of time. And once the deposit and lending interest rates fully liberalized, the central bank's only interest rate control monetary policy tool will no longer exist, for this situation, the central bank still proposed to further guide and control the market interest rate target. At this situation, the creation of standing landing facility reflects the central bank's needs. With the help of regular lending facilities, the central bank can build a "interest rate corridor" to guide the market interest rate. At the same time it will be reasonable to combine facilitate lending with open market operations, re-lending, rediscount, short-term liquidity and other monetary policy tools. And it will helpful to management and regulation of the liquidity of the banking system, to strengthen communication with the market and the public, and to in- 
crease the central bank monetary policy operation transparency. In a word, standing landing facility is expected to promote the smooth operation of market interest rates.

\section{Conclusion}

Although the role of the current means of lending facilities is mainly reflected in the relaxation of short-term liquidity tension, ironing the abnormal economic activities, but with the acceleration of interest rate marketization reform, the platform left for standing landing facility tools will be broader. Moreover, the direction of developing SLF will turn to expanding the type of collateral, constructing a multi-level operation cycle, and expanding the operation of the object.

\section{References}

[1] Ma, L. and Liu, Y. (2014) A Literature Review to the Research of Lending Facility. World Economy Studies, 9, 23-27. http://dx.doi.org/10.13516/j.cnki.wes.2014.09.004

[2] Zhang, C.S. (2010) New Frontiers in Study of Monetary Policy Transmission Mechanism-A Critical Review of the Recent Research in the Background of the New Global Financial Crisis. International Economic Review, 5, 110-120.

[3] Wu, T. (2008) On the Effectiveness of the Federal Reserve's New Liquidity Facilities. Social Science Electronic Publishing, New York.

[4] Liu, S.H. (2009) Innovation and Enlightenment of Fed's Monetary Policy Tool in Financial Crisis. Studies of International Finance, 8, 10-16.

[5] Chen, T (2010) Monetary Policy during the Global Financial Crisis-Comparison between China and the U. S. Asia-Pacific Economic Review, 4, 77-82. http://dx.doi.org/10.16407/j.cnki.1000-6052.2010.04.024

[6] James, M., Asani, S. and Wang, Z.Y. (2008) The Effect of the Term Auction Facility on the London Inter-Bank Offered Rate. Journal of Banking \&Finance, 54-70.

[7] Li, R.Y. (2013) Innovative Liquidity Management Tools: SLF. China Forex, 22, 74-75.

Submit or recommend next manuscript to SCIRP and we will provide best service for you:

Accepting pre-submission inquiries through Email, Facebook, LinkedIn, Twitter, etc. A wide selection of journals (inclusive of 9 subjects, more than 200 journals) Providing 24-hour high-quality service User-friendly online submission system Fair and swift peer-review system Efficient typesetting and proofreading procedure Display of the result of downloads and visits, as well as the number of cited articles Maximum dissemination of your research work

Submit your manuscript at: http://papersubmission.scirp.org/

Or contact jssm@scirp.org 